Article

\title{
Sustainable Smart Cities and Energy Management: The Labor Market Perspective
}

\author{
Olga Pilipczuk@ \\ Institute of Management, University of Szczecin, 71-004 Szczecin, Poland; olga.pilipczuk@usz.edu.pl
}

Received: 26 October 2020; Accepted: 17 November 2020; Published: 20 November 2020

check for updates

\begin{abstract}
Nowadays, sustainability is one of the strategic goals of smart cities. They are the essential solution to creating the sustainable future. On the other hand, the smart city is intended to deal with the problems of energy management. This paper examines the influence of the smart sustainable cities concept on energy management from the labor market perspective. The paper fulfills the research gap about energy manager profession transformation considering smart sustainable city concept. The aim of the paper is to create an up-to-date holistic energy manager skill model with a focus on emerging technologies. The skill model reflects the synergy of two methodological approaches: the theoretical and practical approaches. Descriptive statistics are used to present the labor market research results. It is concluded that the core elements of the smart sustainable city concept have an impact on energy management are sustainability and big data. The labor market research also draws differences in the amount and structure of demand on energy manager skills by countries, but at the same time similar skills requirements are found. The skill model of the energy manager profession is built around several main groups associated with specific knowledge, social skills, and behavior skills. The findings of the present research can contribute to knowledge and practice by applying it in the process of developing energy manager competency models in commercial and non-commercial enterprises as well as in education programs and training courses.
\end{abstract}

Keywords: energy management; sustainability; smart city; labor market; energy manager

\section{Introduction}

Energy is the world's largest industrial sector, representing about 70\% of the world GDP [1]. Energy management issues are currently a contemporary challenge, especially the connection of smart cities and energy management. On the other hand, "energy management is one of the most demanding elements within urban centers owing to the complexity of the energy systems and their vital role" [2]. Unfortunately, according to Deloitte, energy management is currently "paused by pandemics". However, it is "poised to prevail" [3].

Smart cities have been widely discussed under the sustainability concept. In energy industry, "the concept of sustainability clearly shows its complex interdisciplinary nature" [4]. Sustainability of energy systems is usually analyzed from an economic, social, and environmental perspective [4]. Access to sustainable energy is necessary for living standards improvement, common development, and economic growth [5].

It also has become a shared understanding that sustainable development comes together with access to sustainable energy [1]. Thus, the concept of sustainable development has been linked to sustainable energy [1].

The sustainable energy development and improvement topic has been investigated in different economic sectors, including transportation, manufacturing, information and communication, agriculture, green inventory, pollution, and material resources [6-8]. 
Smart cities have also been discussed under the intelligence concept, "related to understanding the dimensions that characterize them, the drivers that enhance their intelligence" [9].

Likewise, artificial intelligence and cognitive technologies play significant roles in energy industry development. It "constitutes a catalyst towards conceptualizing and generating innovative applications and services for energy management and energy-efficient buildings" [10].

Deloitte highlights the role of cognitive technologies in the oil and gas sector [11], pointing out that the "optimized energy flow out to batteries and points of consumption as the potential future applications" [11].

IBM company shares Deloitte's opinion. IBM executives state that cognitive IoT creates the insufficient opportunity for the gas and oil industry [12]. "Cognitive IoT is a way of using machine-learning approaches to analyse and learn from data from a multitude of sources" (IBM oil and gas SME) [12].

According to IBM Institute for Business Value research, in 2016, “94\% of oil and gas executives familiar with cognitive computing believe that it will play a disruptive role in the oil and gas industry" [13]. They also highlight the role of cognitive computing for big data management in smart environments [13].

The smart sustainable city concept could be discussed from the energy manager profession perspective. Energy executives point out that for them "the biggest opportunity is using innovative solutions that not only deliver attractive energy savings, but also a wider range of tangible and measurable business benefits" (James Tiernan, group energy \& environment manager, Unite Students) [14].

Dan Fernbank, Energy and Sustainability Manager at the University of Reading, noticed the importance of innovative solutions: "a key challenge for us is to look at more innovative funding solutions for sustainability projects with more constraints on internal budgets" [14].

Moreover, some authors introduce the definition of smart city manager profession and describe the main responsibilities and skills of the smart city manager and the role he/she will play in the future [15]. According to the research of Michelucci, De Marco, and Tanda, who studied the main skills and competences currently required for a smart city manager position, "the smart city manager's responsibilities and curricula are overlooked" [15]. The authors used the questionnaire method for the main competencies and skills required analysis. They defined the following skills needed: ICT, economic know-how, regulations, principles of procurement, finance, open and big data, urban planning, energy efficiency, project management, sustainable building, public spaces management, and languages. They also highlighted the importance of the following social skills: leadership, personality, and relationship capabilities [15].

The report of the Smart Sustainable Development Model created in 2018 represents the model as a bridge between smart development and sustainable development and their main challenges and opportunities in disaster management. The authors highlighted how important this model is in contributing to the successful implementation of the Sustainable Development Goals [16].

Several journals as well as special issues aim to increase the amount of research on this topic, for example the Special Issue of Sustainability by Daniel Pérez González “Energy Economics and Innovation of Smart Cities" [17].

Above all, in the literature on energy sector, there is still a research gap in the influence of emerging technologies on energy management from a labor market perspective, especially in terms of the sustainable smart city concepts. Moreover, there is a lack of scientific research on the current skills and abilities of energy managers.

To analyze the main aspects of the transformation of energy manager profession and the impact of emerging technologies and smart sustainable city concept on energy management, in this paper, a research study is presented. The hybrid research approach based on the literature study and labor market analysis was used. As a result of emerging concept impact analysis, the skill model was created. Scientific papers and non-scientific literature sources, such as reports and experts' opinions, 
were considered. The labor market study was based on job searching website analysis. Therefore, the final results of the research could have significant practical implications.

The paper is structured as follows. First, the research framework is presented, and the main steps of the research procedure are described. After that, the results of the literature study are presented, outlining the issues raised by the research on the influence of sustainable smart cities concept on energy management. The literature study is followed by the labor market research and the discussion of the results and limitations of this research. Finally, conclusions and the ways of possibility of research continuing and enlarging are discussed.

\section{Materials and Methods}

The research framework was related to two methodological approaches: the theoretical and practical approaches (Figure 1).

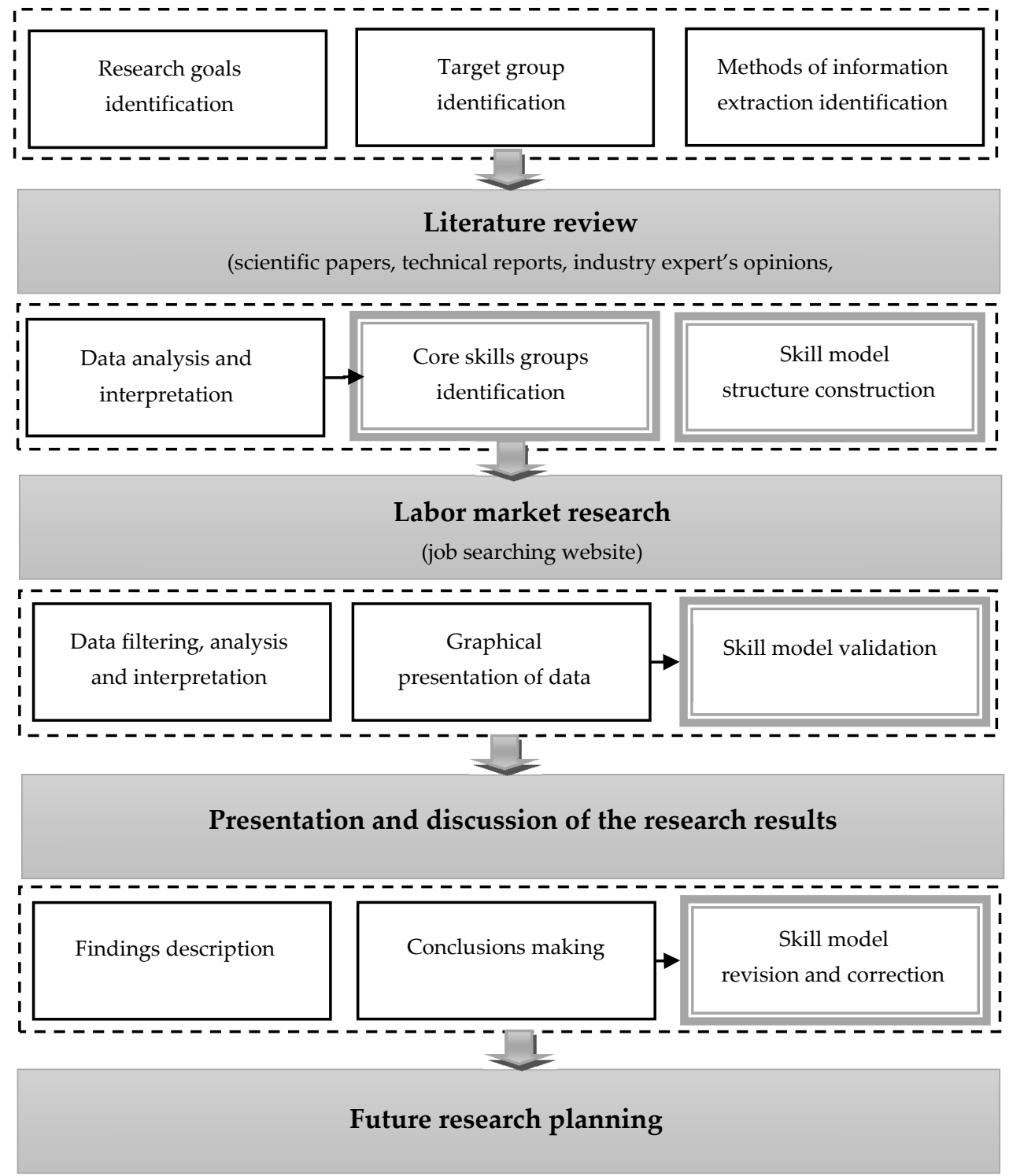

Figure 1. The research framework. 
It was constructed in line with the procedures applied in scientific works [18-24] and the methodological requirements presented in this literature on the subject [19-23]. In [19], the authors, referring to a wide range of literature on the subject, defined the basic stages of model development: design (initial) stage, development stage, preparation stage, implementation stage, and validation stage. In [21], the authors highlighted the importance of initial and validation stage.

In [19], the authors defined the main steps of their research, which aimed to create the competence model, as defining the objectives, defining and planning the methodology, creating the model, implementation, evaluation, and continuous improvement.

In [24] the authors discussed the competence model hierarchical structure. They argued that all competencies should be clustered into several main groups of competencies and divided into further categories.

The first stage of the procedure covers the research objectives identification and target group selection. The target group of energy managers job positions was chosen. At the same stage, data collection methods were selected. Among different methods, the literature review and labor market survey were chosen to fulfill the research gap. At the next stage, the literature study was conducted, and the skill model main structure was created. The general structure of the model was constructed by integrating the skills into main groups and subgroups and providing appropriate competencies for each group.

To evaluate the literature study results, labor market research was conducted. At this stage, data filtering, analysis, interpretation, and graphical presentation were used. In other words, the skill model validation was carried out. The last stage was the model revision and correction. The skills and abilities that frequently appear in job posts and were not identified earlier as a result of the literature study were added to the model. The abilities that do not appear in the labor market analysis were excluded from the model.

\subsection{Literature Review}

In scientific research, energy management is considered as a key element of complex energy systems for smart cities [25].

The review of energy big data digitalization systems in the energy sector reveals the challenges mentioned in the managing of volume, variety, and velocity of the data [26]. "Therefore, big data is the essential technology to realize the paradigm shift in the energy sector" [27]. Some papers investigate the energy big data sources. In [26], the authors distinguished two groups of data sources: electric utility data and supplementary data $[26,28]$. Supplementary data could be obtained from such data sources "as geographical information system (GIS) data, global positioning system (GPS) data, time-reference data, weather and lightning data, seismic reflection data, animal migration data, financial market data, social media data and regulatory reporting data" [26].

Several essential technologies support the introduction of big data applications to the energy sector [29,30]: smart grid, Internet of things (IoT), and cloud computing [31-33].

Big data accompany the different processes in the energy industry starting from production, through logistics, and to consumption [34]. Actually, big data technologies help process continuous improvement, for example by influencing the increase of fuel efficiency [35].

In the energy sector, big data are coordinated, analyzed, and effectively applied to big data analytics. These analytics provide sophisticated energy services [36,37]. Big data analytics helps generate accurate forecasts of energy consumption, which affect power generation from renewable energy sources and pricing $[10,27]$.

Moreover, it was observed that "big data technologies - combined with artificial intelligence, namely the new 'engine' of the Fourth Industrial Revolution and IoT infrastructure management enablers-constitute a catalyst towards conceptualizing and generating innovative applications and services for energy management" [38], especially in terms of sustainable development. 
The book "Energy management for sustainable development" provides a forum on policies and strategies as well as technologies to describe and discuss energy management issues in terms of achieving sustainable development in many energy sectors [39]. The authors discussed the current environmental problems among many countries, such as China, Nigeria, the United States, Taiwan, and those in the sub-Saharan region, and proposed various ways solutions.

Many authors highlight the meaningful role of big data technology applications for design, planning, and managing smart and sustainable cities [40-43].

The sustainability concept, urban growth, and technological development have been converged under the "smart sustainable cities" concept $[44,45]$. Such a city "is supported by the massive use of advanced ICT in connection with various urban domains and systems" [44].

In their work "Towards sustainable smart cities" [41], the authors described the main trends and current challenges taking place in the smart city concept. They also discussed premises for the convergence of sustainability and smart city concept creating a new one "sustainable smart city" concept. They described the architecture, main characteristics, and the ways of implementation of smart city projects into the practice.

In [42], the authors discussed the role of smart energy systems for sustainable smart cities. They concluded that a smart city needs intelligent approaches to manage and coordinate the diverse range of technologies applied.

Detailed overviews of different aspects of sustainable and smart cities are offered in the Sustainable Cities and Society (SCS) journal. This international journal presents many works with the focus on "fundamental and applied research aimed at designing, understanding, and promoting environmentally sustainable and socially resilient cities" [43].

The authors of [46] described the current developments in the smart energy sector, highlighting emerging key challenges and outlining future perspectives for the industry. Among many others, they argued "that smart city need for intelligent approaches to manage and coordinate the diverse range of supply and conversion technologies".

"A smart city is a city that uses technological advances (such as IoT, big data, cloud computing, AI, etc.) to transform itself into an innovative ecosystem, concerned with achieving the wellbeing of its citizens, with special attention to sustainable development" [47].

The authors of [48] stated that the smart city concept has been introduced as a model for developing the city of the future, and most improvements and transformations in this model are based on energy aspects.

Forty-three smart city definitions, assessed according to the different dimensions of sustainability, were identified [49].

The authors of $[50,51]$ described the fundamental and synergistic elements of a smart city: the technology, economy, and management of energy resources that allow sustainable development, as well as the perception and social concern about these issues.

The authors of [52] provided guidelines for energy management and how to help an organization improve its energy and financial performance in a way to distinguish the organization as an environmental leader. In [9], the authors provided 16 guidelines of smart city statute for increasing its intelligence and making them smarter.

The authors of [53-56] analyzed the relationship between the smart city and the concept of energy sustainability and confirmed the correlation of these two concepts.

Some papers are focused on smart city solutions challenging with mobility problems $[57,58]$. The authors of [57] presented a reference framework which supports the decision-making processes of public and private organizations. This framework serves as the basis for design and development of the proposed smart city mobility solution.

Several works highlight the emphasis of big data on geospatial systems [59-62]. They are the essential element of the smart city. Geospatial big data systems work with many geospatial data retrieved from a smart city environment. 
The cognitive technologies create the next opportunity for increasing the energy management efficiency. "Fuzzy cognitive map is an established methodology for scenario analysis and to support a decision-making process in energy industry" [63]. Cognitive radio systems are tools for energy-efficient design of channel sensing [64,65]. The cognitive technologies are also helpful during the renovation phase of buildings. "The cognitive layer defines the appropriate rules for opening and shading using the decision tree algorithm applied to the data generated by the sensors in order to infer users' preferences" [66]. Cognitive visualizations help to provide the appropriate information interpretation in the gas and oil industry [67]. They are able to present large amounts of information in terms of one energy manager dashboard.

Moreover, the relationship of artificial intelligence and sustainability has been highlighted by many authors [68-71]. Artificial technologies have also been used for prediction in energy industry.

According to Accenture, "As artificial intelligence takes on an increasing number of tasks, managers will likely need to strengthen innately human skills—such as collaboration and social networking" [72].

Another technology that has a growing influence on energy management is IoT. The energy demand of IoT applications is increased, while IoT devices continue to grow in both number and requirements. Therefore, smart city solutions must have the ability to efficiently utilize energy and handle the associated challenges [25].

The authors of [73] presented "the efforts on optimizing energy consumption by deploying an energy management system using the current IoT component/system/platform integration trends through layered architecture".

The authors of [74] argued that IoT "transforms simple building energy management into smart building energy management". It also helps increase the building's security, which helps to provide "real-time/predictive visualizations integrating historical IoT sensor data with real-time IoT sensor data".

Another paper provides a framework for energy-efficient optimization and scheduling of IoT-based smart cities [25]. It also discusses the energy harvesting in smart cities, "which is a promising solution for extending the lifetime of low-power devices and its related challenges" [25].

Moreover, "IoT can help to improve energy efficiency, increase the share of renewable energy, and reduce environmental impacts of energy use" [75].

The authors of [76] described the sustainable environment for IoT and provided an overview of green IoT and "the challenges that are faced due to excessive usage of energy hungry IoT devices" [76]. "Green IoT envisions the concept of reducing the energy consumption of IoT devices".

Cognitive IoT is a relatively new domain of research and has not been explored enough to analyze deeply its influence on energy management [77]. The authors of [77] made attempts towards providing cognitive solutions for IoT usage.

In recent years, the new concept of Internet of Energy (IoE) appears. "IoE will allow energy exchange between a wide variety of sources and loads, including renewable energy sources, distributed energy storage, plug-in electric vehicles, domestic and industrial "prosumers" [78].

To apply the above-mentioned emerging technologies in practice, enterprises need experienced energy managers with strong interpersonal skills "to build teams, foster innovation, and encourage new ways of working" [79].

Summarizing the results obtained from the literature study, it was concluded that the main elements of the smart sustainable city concept which currently have significant impact on energy management are sustainability, big data, smart cities, artificial intelligence, and IoT.

However, technologies such as IoT, cloud computing, and cognitive computing are treated rather as technology solutions, not concepts in light of the energy manager profession.

Actually, the role of the energy manager has changed significantly. "In the 1970's, the role of the energy manager was typified as a fire fighter using crisis management to keep the industry going" [79]. With changing in energy analysis and valuation methods [80], new concepts were created [81], which changed energy management programs and policies and created new directions for energy managers in 
the 1980s [79,82]. Today, an experienced manager combines technical skills with expertise in financing, planning, strategy, communication, public policy analysis, creation, and interpretation $[80,83]$.

Despite this, there is a lack of scientific papers on the challenges of energy manager profession transformation.

Dalton et al. highlighted the cross-cultural nature of today's energy manager profession. They noticed the importance of law knowledge and value and social systems of different cultures/subcultures [82]. The authors of [84] described the interdisciplinary nature of smart organization and management in smart cities.

Ballini et al. described the role of energy manager and the meaning of resource management and ISO 50001 standard for energy managers [83]. They proposed to use the results to develop future training and educational programs aimed to energy managers.

The role of an energy manager has changed also under the influence of complex digital control systems development [85]. "Fulfilling the potential of these systems requires their operators to have the appropriate skills, which requires support for career-long learning" [85].

More information on concrete abilities, competences, and skills are provided in several technical reports, studies, and articles [86-94].

First, the experts noticed that, "to establish a successful energy program, the energy manager must have a good understanding of both the technical and managerial aspects of energy management" [86].

According to Global Superior Energy Performance Partnership research [87], energy managers need to have skills on every stage of the energy management process "from initiating an Energy Management Program, conducting an energy review, energy management planning, implementing energy management to measurement and verification".

The authors of [88] pointed out the meaning of the following skills:

- "Social and behavioral skills: communication skills, technical leadership skills, organizational skills, time management, facilitation skills, setting priorities, strategic planning, team building, reading and comprehension, proficiency, conflict resolution, develop and track energy goals, analytical and policy interpretation skills".

- “Technical knowledge: math, algebra, statistics, data, energy concepts knowledge, strategic planning, analysis and trending, software skills, electrical, mechanical and process skills, and business fundamentals".

- "Project management (budgets, schedules, basic project costing, financial calculations, develop and manage project resources, project management software skills".

- Plant economics.

- Research skills.

In their curriculum [89], the authors mentioned the following skills requirements: project management, risk management, relationship management, BPM, change management, product management, IT management, software engineering, data analysis (statistics and big data), IT in production, energy technology standards, fundamental energy principles, energy measurement and assessment, energy effectiveness improvement, future energy prediction, energy systems projection, construction energy systems, and investigation of energy sustainability.

The technical skills and competences for a chief executive officer of energy according to Singaporean Skills Future Movement are [90]: business planning management, problem solving skills, business stakeholder management, communication skills, business-to-business customer relationship management, decision making skills, continuous improvement management, sense making, advanced crisis management, emergency response management, resource management, risk and compliance management, and safe system of work development and implementation.

The model proposed in Global Superior Energy Performance Partnership research [87] compares the skills needed in several countries such as Australia, the United States, Japan, Korea, and South Africa. The study reveals great differences in competence requirements. The model of competence 
was structured according to the energy management cycle. The highest requirements for energy manager job positions were noticed in Australia and the United States. In Australia, for example, energy management, change management, risk management, contract management, innovation skills, problem solving, communication, analytical, interpersonal, energy procurement knowledge, energy accounting, waste management, water management, and many other skills were required.

Moreover, ARCADIS underlines the importance of procedures and policies knowledge for energy managers. According to ARCADIS opinion, "the energy manager should be able to establish, implement and maintain its own procedures, conformity with the energy policy, and procedures, and the requirements of the Energy Management System" [91].

On the other hand, according to the Australian Government, Department of Industry, Science, Energy and Resources, the energy manager is a person "with skills in communications, financial administration and information systems, and an understanding of technology" [92].

Moreover, the Canadian Ministry of Natural Resources highlights the role of energy management training within enterprises. The Ministry states that "the one of the best ways to improve energy efficiency is through energy management training - that is, by making sure the staff are equipped to take full advantage of the energy-saving opportunities available to organization" [93].

Currently, energy managers rather act as business partners instead of task managers [94].

Energy managers should be up to date with current concepts and technologies. New concepts which have influence on energy sector appear in the last decades include sustainable value management [95], sustainable supply chain management [96], sustainable decision-making, smart sustainable city, intelligent energy management [97], etc.

Summarizing the results of the literature review, it could be concluded that the energy manager profession is currently characterized by the following features:

- It needs continuous learning and requires high learning abilities.

- It is under the influence of emerging concepts and requires new concept knowledge.

- It is under the influence of emerging technologies and requires advanced IT skills.

- It requires financial and accounting knowledge.

- It requires procedures and policies knowledge.

- It requires strong leadership and communication skills.

- It requires strong analytical skills and statistics knowledge.

- It requires strong technological skills that depend on the sector and common mathematical and technological knowledge.

- It requires different management skills.

- It requires the abilities related to projecting new energy technologies and policies and research skills.

- It often has a cross-culture, international nature and thus requires language knowledge.

The growing popularity of the smart sustainable city concept is causing changes in the energy manager profession. The literature analysis reveals that many experts underline the need of continuous learning and skill improvement for energy managers. This profession asks for very skillful executives with knowledge in different domains and emerging concepts, such as big data and sustainability.

In this way, the energy manager becomes one of the most challenging professions of the future.

The core competencies and skills required for executive positions in the energy sector were found and selected for further validation.

Finally, the following skills were selected from different sources:

- $\quad$ Technical knowledge $[86,88,89,92]$ : Energy systems engineering $[87,89,93]$, ISO 50001 and 50002 [83], energy concepts knowledge [86], plant economics [88], urban planning [15], energy conservation [14], electrical systems [87], building systems [87], advanced and renewable energy technologies [14], energy auditing, procurement $[15,87]$, etc. 
- $\quad$ Law knowledge [94]: Regulations and policies [86,94].

- Management knowledge [87,90]: Energy management [87]; sustainable management [87]; BPM [89]; change management [89,90]; project management [88]; data, information, and knowledge management [89]; risk management [87,89,90]; product management [89]; CRM [89]; contract management [87]; asset management [90]; crisis management [90]; resource management [90]; emergency management [90]; waste management [87]; water management [87]; etc.

- IT skills [89]: Energy modeling and design software [14], big data [13], project software [88], new product design tools [87], cognitive analytics [12,13], artificial intelligence [11-13,72], software implementation skills [90], cloud computing [90], IoT [13], data mining and visualization [67], geospatial big data tools [67], etc.

- Emerging concepts knowledge [15,86,89]: Sustainable development [89], sustainable decision-making [87], sustainability accounting [87], etc.

- Financial knowledge [92]: Financial analysis [83], costing, budgeting, financial modeling, forecasting, financial strategic planning [83], and accounting principles [87].

- Research skills [88]: Data analysis and interpretation skills, research methodology knowledge, conclusion making skills, etc. [88].

- Social and behavioral skills [88]: Problem solving [87,90], leadership skills [88], decision-making skills [87], communication skills [90,95], team building skills [88], organizational skills [88], improvement skills [87], critical thinking skills [87], interpersonal skills [87], negotiation skills [87], analytical skills [88], cross-cultural communication skills [82,84], motivation skills [87], ethics knowledge [87], and setting goals [88].

In the next section, these competences are checked and analyzed by means of labor market research.

\subsection{The Labor Market Research}

The research was conducted in the summer of 2020. The first results were obtained at the beginning of July, and after that they were checked twice until the end of August. The procedure in line with the framework presented in Figure 1 was used.

In the first stage, the most popular worldwide job search websites (according to the worldwide rankings) using Google search were selected. The following selection criteria were used: (1) the largest number of current energy executive published job posts; (2) applicability in the studied countries; (3) clustering by industry (already defining separately the "Energy" job group for energy sector); and (4) the ability to support "advanced search". The use of English language in job posts also had a significant influence on the final choice.

The website comparison was carried out. Consequently, "Indeed" job search website was chosen. The jobs were browsed by "Energy" job group.

In this stage, the task was to acquire the similar requirements in energy manager skills among different continents and countries. The country selection was conducted according to the following criteria: geographical position (different continents and different European regions), technological development level, and high GDP level. The following countries were considered: the United States of America, Canada, Poland, the United Kingdom, France, and Germany. However, According to European Commission Joint Research Centre "the labor market impact of COVID-19 have been expected to be higher in some Southern European Member States and Ireland" [98]. Thus, the European countries which noticed the high impact of COVID-19 (contracts lost) in July, such as Greece, Bulgaria, Romania, Spain, Slovenia, Ireland, and Italy, were excluded from consideration [98].

About 352,000 job posts were processed. Job posts were filtered using "Indeed" website search engine by entering the following key words into the webpage search field: "artificial intelligence", "sustain(ability)/(able)", "smart city", "big data", "large data", "large data sets", "large amount of data", etc. The position analysis was done with the following key words defined: "energy manager", "energy director", and "energy executive". An identical research procedure was used for all selected countries. 
The website searching mechanism found many relevant positions, such as sustainable materials manager, sustainable and environmental manager, sustainable strategy manager, sustainable project manager, sustainability solutions manager, energy performance manager, climate change manager, and energy efficiency manager.

In the next step, the number of job offers for energy executives (EE) and relevant positions including appropriate skills requirements were calculated. The amount of demand on energy managers positions reflects the influence of different concepts on energy management among countries. The results are presented in Table 1. The column "Energy" presents the total number of offers in the energy sector and the number of offers for executives according to the website search engine by country. The following columns present the number of job offers requiring skills in artificial intelligence, big data, smart city, and sustainability concepts.

Table 1. The results of information acquisition using the "Indeed" website.

\begin{tabular}{cccccc}
\hline \multicolumn{5}{c}{ Number of Job Offers } \\
\hline Countries & Energy & AI & Big Data & Smart City & Sustainability \\
\hline UK total & 13,637 & 252 & 419 & 124 & 508 \\
executives & 5107 & 63 & 31 & 63 & 240 \\
\hline DE total & 39,766 & 233 & 494 & 67 & 1186 \\
executives & 3371 & 15 & 84 & 32 & 184 \\
\hline FR total & 16,401 & 83 & 216 & 176 & 141 \\
executives & 2245 & 10 & 37 & 8 & 19 \\
\hline PL total & 697 & 3 & 3 & 0 & 58 \\
executives & 297 & 0 & 0 & 0 & 10 \\
\hline CA total & 10,200 & 139 & 221 & 53 & 789 \\
executives & 3796 & 48 & 136 & 24 & 372 \\
\hline USA total & 271,615 & 1569 & 4270 & 722 & 12,504 \\
executives & 102,485 & 567 & 2198 & 235 & 5051 \\
\hline
\end{tabular}

In the final stage of labor market research, the presence of competencies identified in the result of literature analysis was checked by adding the key words with competence titles to energy manager positions. For example, "energy manager", "project management" or "energy manager", "communication skills", etc. are skills that appear in job posts and were not identified earlier as a result of a literature study, and thus were selected for further processing. The abilities that were identified during the literature study but did not appear in the labor market analysis were excluded from further processing.

\section{Results}

The greatest number of vacant job posts in energy sector was found in the United States, along with energy manager (executive) job posts (Table 1 and Figure 2).

In the United States, the United Kingdom, Canada, and Poland, energy executive vacancies account for about $30 \%$ of the total vacancies. In France and Germany, the executive group is less numerous and accounts for about 10-20\%. In these countries, engineers and operational workers in energy sector are more in demand. 


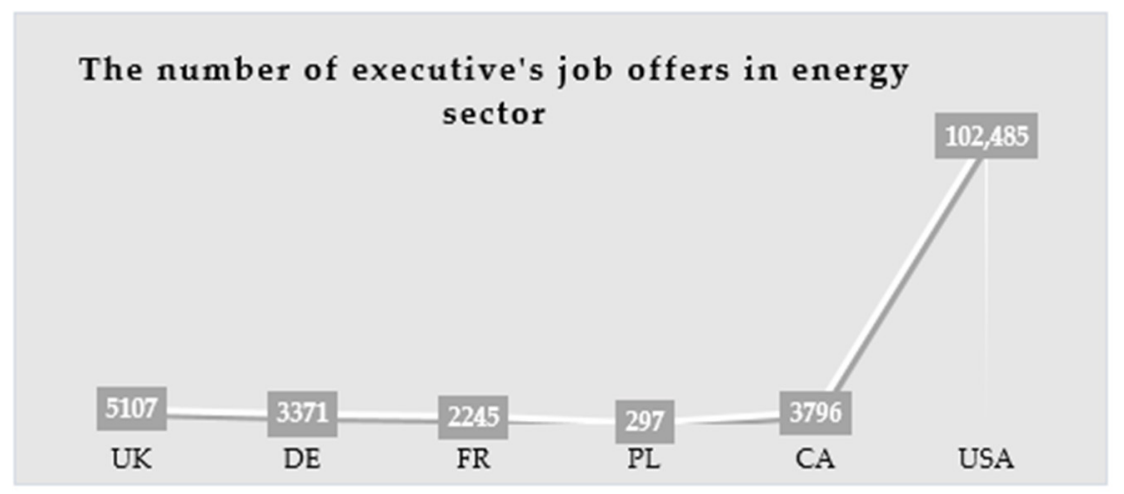

Figure 2. The number of job offers for executives in energy industry.

The most popular requirement among the studied concepts was the sustainability concept (Figures 3-8). France was an exception, where specialists with big data concept knowledge were the most wanted (Figure 7). The great predominance of sustainability concepts in Poland was also noticed.

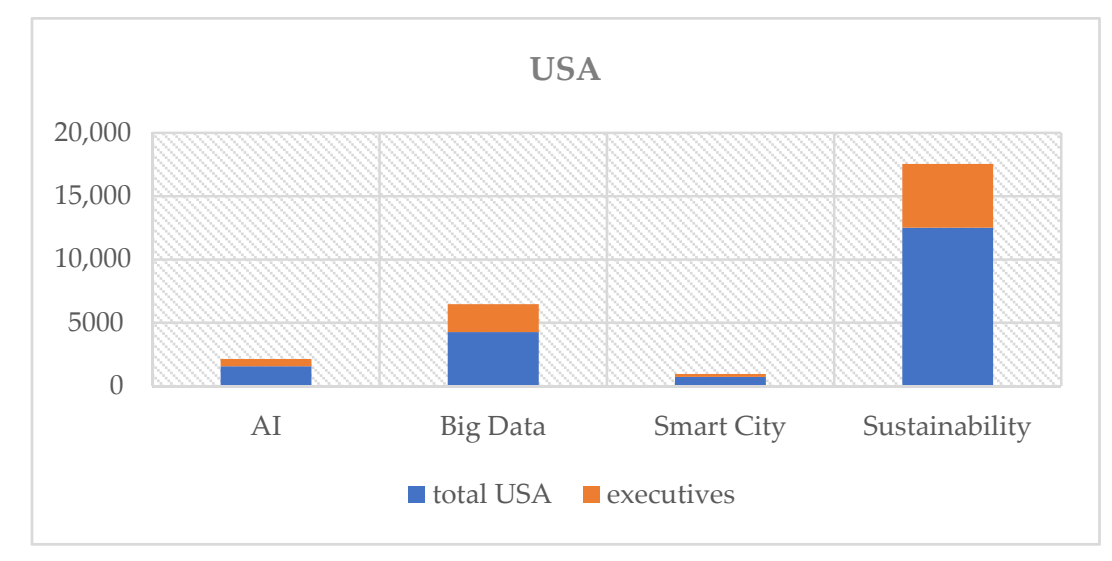

Figure 3. The number of job offers in the energy sector in the United States with selected skills required: the total number and the number of job posts for executives.

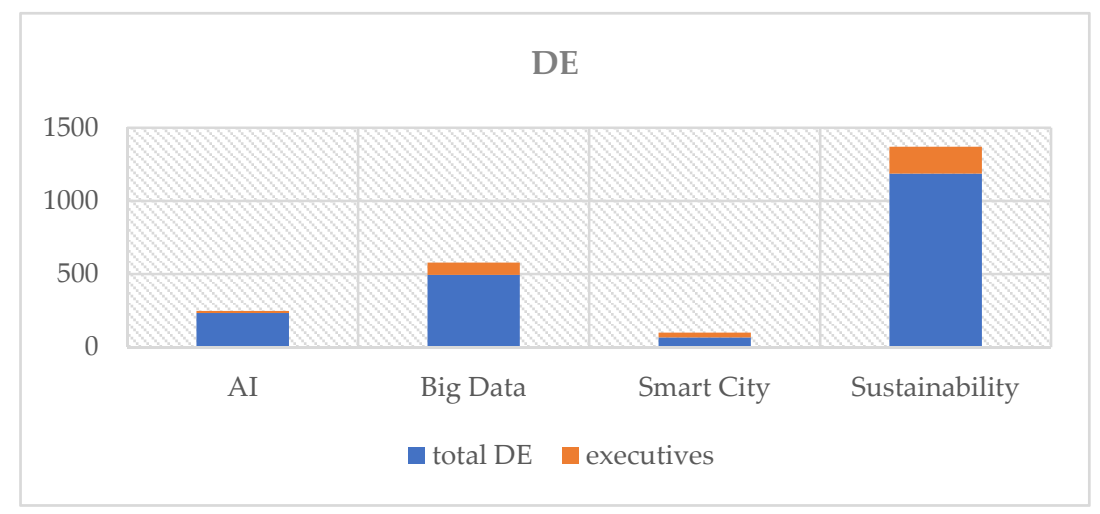

Figure 4. The number of job offers in the energy sector in Germany with selected skills required: the total number and the number of job posts for executives. 


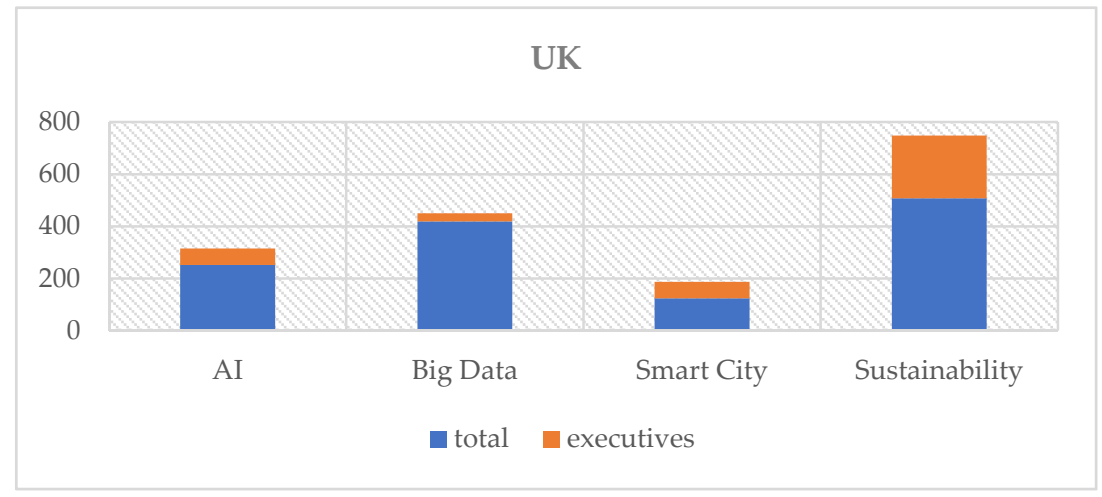

Figure 5. The number of job offers in the energy sector in the United Kingdom with selected skills required: the total number and the number of job posts for executives.

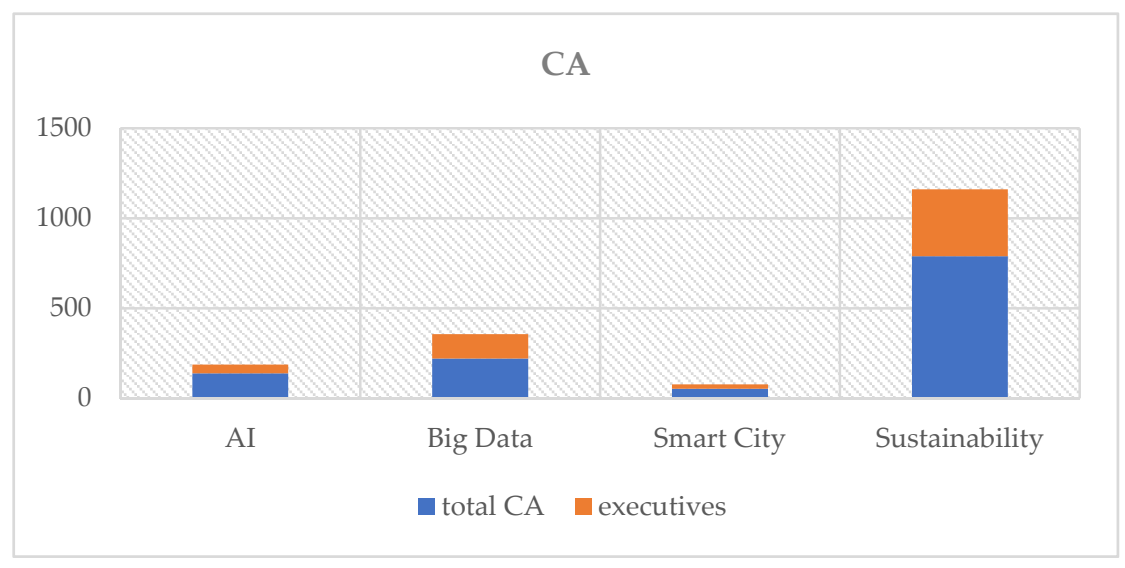

Figure 6. The number of job offers in the energy sector in Canada with selected skills required: the total number and the number of job posts for executives.

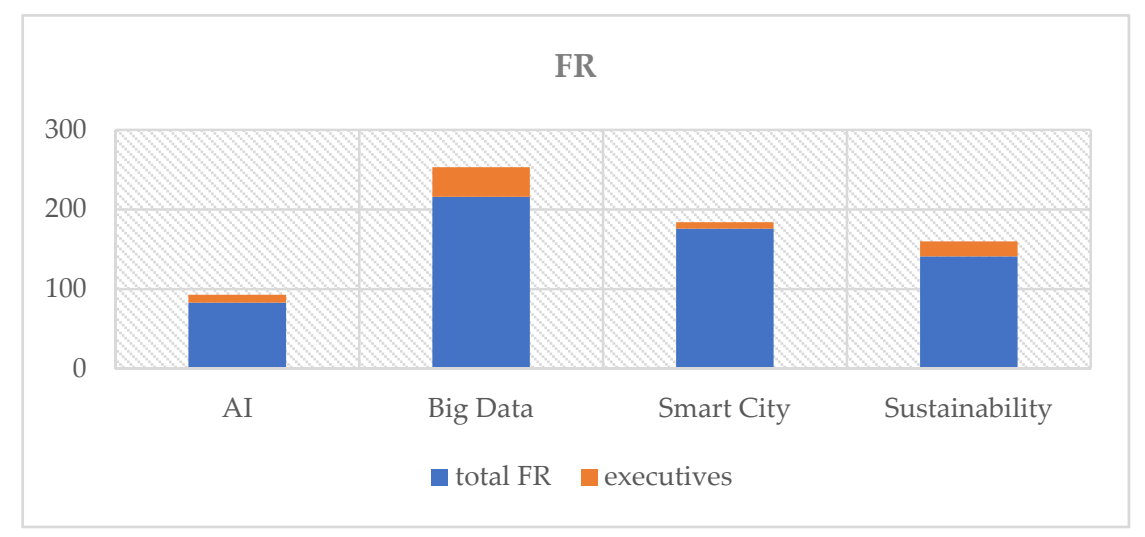

Figure 7. The number of job offers in the energy sector in France with selected skills required: the total number and the number of job posts for executives. 


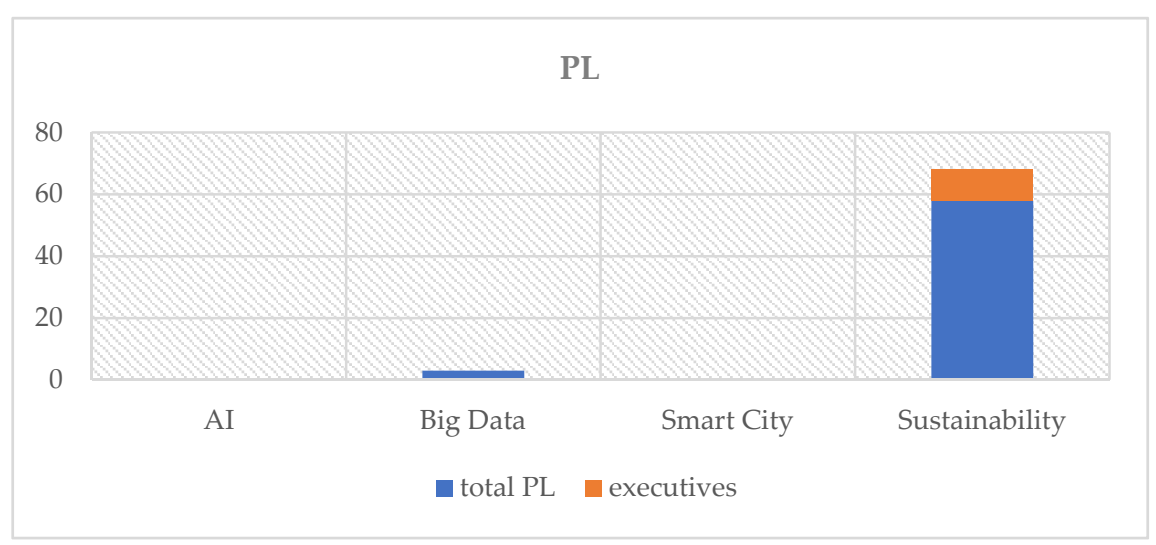

Figure 8. The number of job offers in the energy sector in Poland with selected skills required: the total number and the number of job posts for executives.

In general, the companies were looking for the skillful technically specialists. Besides the big data, artificial intelligence and smart technologies, many requirements were related to energy systems design software, such as Rhino, Grasshopper, Ladybug, Honeybee, DIVA, and SketchUp, as well as new product design software, such as Adobe Creative Suite, Photoshop, Publisher, and AutoCAD. The skills in GIS software, such as ArcGIS and Google Earth, were under great demand. Sometimes the companies required cognitive analytics software skills, for example Cognos and Tableau. They also were looking for experts with extensive knowledge in the management areas (Figure 12).

In the next step, the share of knowledge of studied emerging concepts (big data, artificial intelligence, smart cities, and sustainability) in the total number of EM job posts was analyzed among countries. The analysis depicts that the Canadian enterprises are most demanding in the sphere of studied concept competences (Figure 9) at 15.3\%, while 9.3\% was calculated for Germany, $7.8 \%$ for the United States and United Kingdom, 3.3\% for France, and about 1\% for Poland.

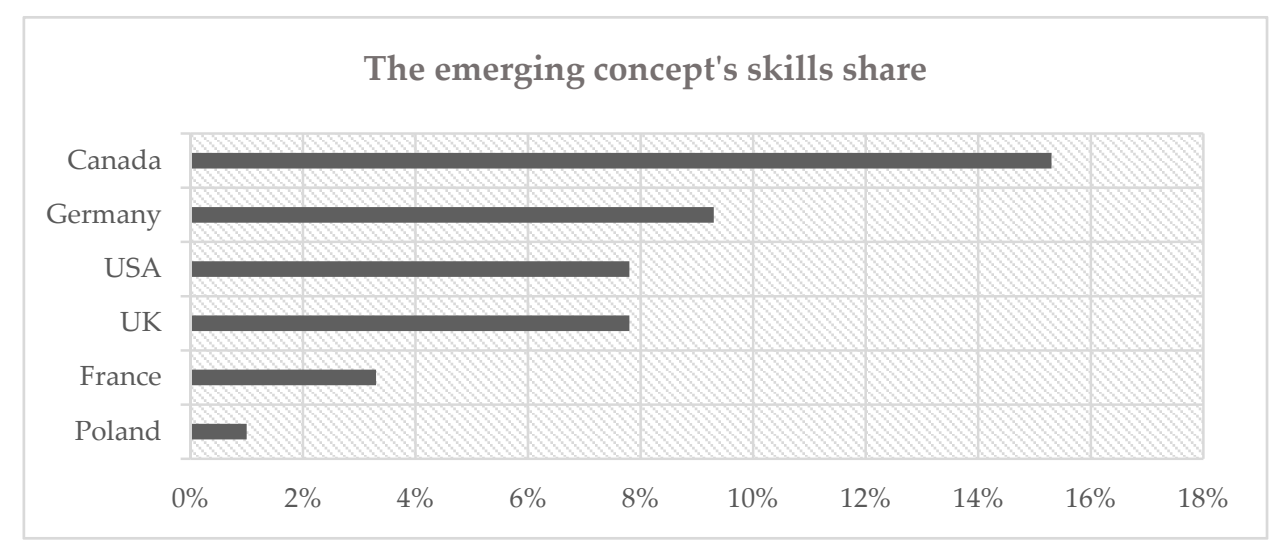

Figure 9. The amount of demand on studied concept skills for energy executives by country.

Furthermore, the spatial distribution of demand intensity of studied concept skills (big data, AI, sustainability, and smart city) was studied (Figure 10). 


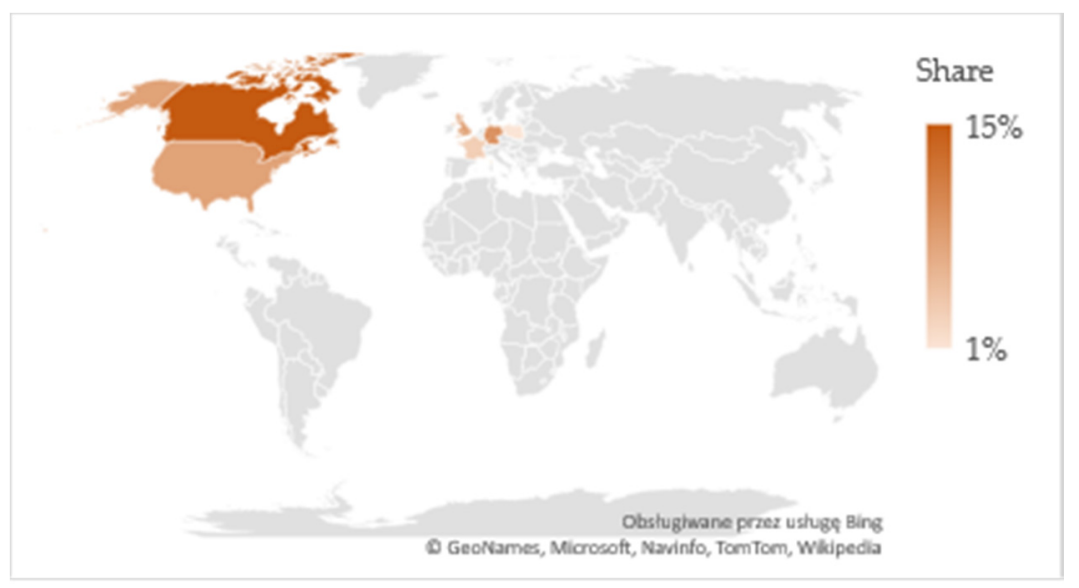

Figure 10. The map of spatial distribution of demand intensity of studied concept skills for energy executives by countries.

The spatial analysis showed no trends in the territorial distribution of the discussed concepts.

Despite the main purpose of this paper being the energy manager skill model creation, more advanced statistics, such as descriptive statistics, Pearson matrix, Spearman correlation, and covariance matrix, were calculated, as presented in Appendix A (Tables A1-A7).

\section{Discussion}

The labor market study has several limitations. The job posts were filtered at the stage when the executive job posts were acquired. The requirements were checked based on clearly defined key words. This resulted in avoiding job posts with unprecise skills definitions. However, it should not have an impact on the developed skill model because the model was created as the result of the synergy of the two methodological approaches. Therefore, it was also proved by the literature study. Moreover, the large number of analyzed job posts guaranteed the sufficient representativeness of the requirements for classifying them in the model. However, in future research, other countries could be considered. Many countries provide job posts in their native language, especially Asian countries. The language limitations had an impact on the country selection process, as did COVID-19. During the research period, the impact of COVID-19 was significant in many European countries, and, a few months later, its common influence was noticed by experts.

It should be noted that, during the labor market research, job posts with IoT skills and cognitive technology skills were found. However, their number was too small to be considered. Moreover, these job posts were rather related to managerial job positions in energy industry, not to energy managers or other executives. The skills of these technologies were usually required for technical positions on the operational level in the energy sector. Thus, it was hard to acquire appropriate results. Despite this, it is possible to analyze these and other emerging technologies related to smart sustainable city concept in the future.

Summarizing the comprehensive results obtained from both the literature study and labor market research, it was concluded that the core concepts related to sustainable smart city concepts which have an impact on energy management are sustainability, big data, artificial intelligence, and smart cities. Figure 11 shows the impact of the studied concepts on energy executive job positions.

The convergence of information technologies creates new concepts involved in the day-to-day operations of the energy sector, such as sustainable smart production, smart meter measurement, smart grids, and many others. The knowledge of these and more modern concepts becomes an important condition of energy manager employment.

During the labor market research, the main skills and competences identified in the literature analysis were checked. The skill model was constructed taking into consideration approaches to 
international competence model building analysis as well as global changes bringing new challenges to skill model building.

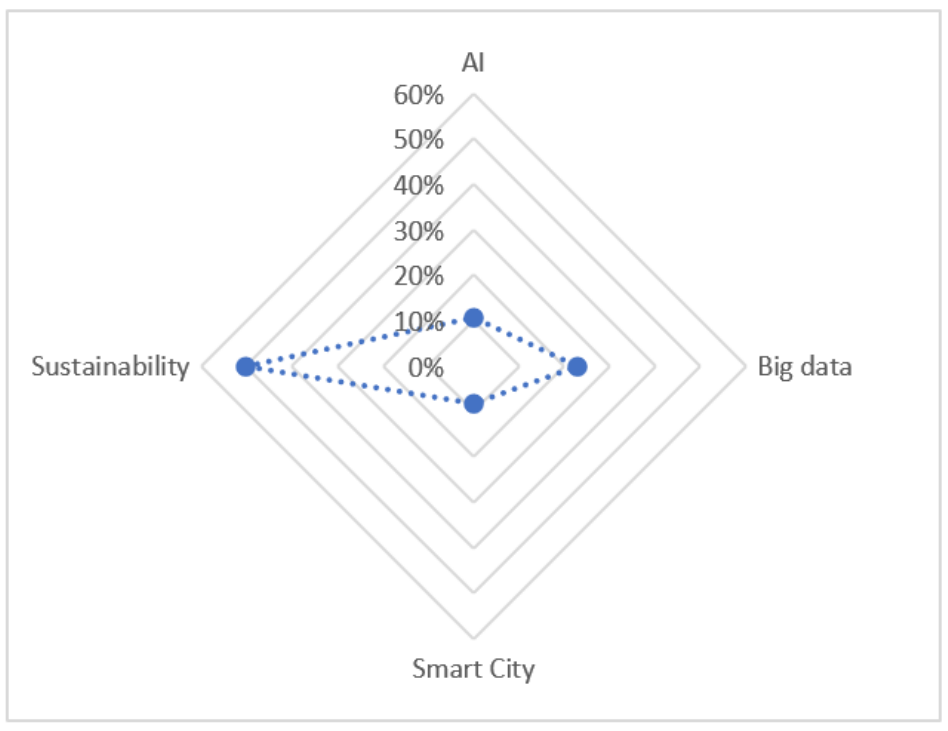

Figure 11. The demand on studied concepts knowledge within energy managers.

There are different approaches to international competence model building. In "Professional Competences: a Classification of International Models" [99], the authors presented the most popular approaches:

- The competence model based on the workplace: in this model, "a series of required standards for each competence are defined" [99].

- The competence model based on behavioral theory: it defines competence "as an underlying aspect of an overall psychology that includes motives, skills, abilities, self-image, and knowledge" [99].

- $\quad$ The competence model based on business strategy [99].

- The competence model based on a cognitive and motivational approach: "It has reflections in the workplace, internal motives, culture, values, and ethics" [99].

- The competence model based on a holistic approach: this model defines competence "as a result of a mix of underlying personal aspects, such as communication, self-development, creativity, conflict analysis and resolution". The model reflects "a holistic approach to competences to consider the complexity of the integration of knowledge, abilities, and skills" [99].

However, according to World Economic Forum, global changes bring new challenges to skill model building. "The accelerating pace of technological, demographic, and socio-economic disruption is transforming industries and business models, changing the skills that employers need and shortening the shelf-life of employees' existing skill sets in the process" [100].

These changes are:

- Demographic and socioeconomic changes: changes in the nature of work (it becomes more flexible), climate change, natural resources, etc. [100]

- Technological changes: the impact of cloud computing, processing technologies, emerging energy technologies, big data, IoT, robotics, artificial intelligence, etc. [101]. The report of World Economic Forum highlights the big data and artificial intelligence technologies impact on global development during 2018-2020 years [102].

Analyzing the above-mentioned models and changing factors, the holistic international skill model for energy managers was created (Figure 12). 


\section{Energy manager skill model}

\begin{tabular}{|c|c|}
\hline $\begin{array}{l}\text { Technical knowledge } \\
\text { (depend on domain) }\end{array}$ & $\begin{array}{l}\text { Energy systems engineering, ISO } 50001 \text { and 50002, smart grids, smart } \\
\text { energy systems, energy concepts knowledge, plant economics, urban } \\
\text { planning, energies conservation, electrical systems, building systems, } \\
\text { and advanced and renewable energy technologies, energy auditing, } \\
\text { procurement etc. }\end{array}$ \\
\hline Law knowledge & $\begin{array}{l}\text { Regulations, policies, degrees, codes in energies: global regulations; } \\
\text { European regulations; country law, provincial regulations. }\end{array}$ \\
\hline Management knowledge & $\begin{array}{l}\text { Energy management, Sustainable management, BPM, Change } \\
\text { management, Project management, Data, Information and Knowledge } \\
\text { management, Risk management, Product management, CRM, Contract } \\
\text { management, Asset management, Crisis management, Resource } \\
\text { management, Emergency management, Waste management, Water }\end{array}$ \\
\hline IT skills & $\begin{array}{l}\text { Energy modelling and design software, big data, project software, } \\
\text { geospatial software, new product design tools, cognitive analytics, } \\
\text { ERP/MRP systems, MS Office, artificial intelligence, software } \\
\text { implementation skills, cloud computing, IoT, data mining and } \\
\text { visualization, geospatial big data tools etc. }\end{array}$ \\
\hline $\begin{array}{c}\text { Emerging concepts } \\
\text { knowledge }\end{array}$ & $\begin{array}{l}\text { Sustainable development, smart city, smart sustainable city, sustainable } \\
\text { decision-making, sustainability accounting etc. }\end{array}$ \\
\hline Financial knowledge & $\begin{array}{l}\text { Financial analysis, costing, budgeting, financial modelling, forecasting, } \\
\text { financial strategic planning, accounting principles. }\end{array}$ \\
\hline Research skills & $\begin{array}{l}\text { Data analysis and interpretation skills, research methodology } \\
\text { knowledge, conclusion making skills etc. }\end{array}$ \\
\hline $\begin{array}{l}\text { Social and behavioral } \\
\text { skills }\end{array}$ & $\begin{array}{l}\text { Problem solving, leadership skills, decision-making skills, } \\
\text { communication skills, team building skills, organizational skills, } \\
\text { improvement skills, critical thinking skills, interpersonal skills, } \\
\text { negotiation skills, analytical skills, cross-cultural communication skills, } \\
\text { motivation skills, setting goals, ethical codes and practices. }\end{array}$ \\
\hline
\end{tabular}

Figure 12. A holistic energy manager skill model.

It consists of two core skill groups: specific skills (depending on domain) and social and behavior skills. The specific skills were divided into several groups: technical knowledge (often related to certification), law regulations, management knowledge, IT knowledge, "new" concepts knowledge, finance, branch knowledge (specific), and research skills.

The skills that frequently appear in job posts and were not identified earlier as a result of a literature study were included in the model. The abilities that were identified during the literature study but did not appear in the labor market analysis were excluded from the model. 


\section{Conclusions}

The global energy system is currently under rapid transformation with "potentially far-reaching implications that will unfold in the next decades". The new EU energy strategy requires the implementation of significant changes within enterprises and creating new technological innovations [103].

The obtained results prove the influence of the sustainable smart city concept development on the transformation of energy management and energy manager profession. Enterprises are already looking for energy executives with knowledge of sustainability and smart city concepts, as well as with big data and artificial intelligence knowledge. This indicates the necessity of introducing changes within not only the enterprises but also education.

Currently, the role of energy manager is extremely extensive and often unprecise. This is especially true in the case of chief executives. Energy managers are seen rather as business partners instead of task managers. Their work is cross-cultural, technology- and regulation-oriented, and research-based. Actually, different countries have different ways of looking for manager positions in the energy sector. Because of the diverse nature of the industry, the requirements largely depend on the domain. This results in the difficulties of holistic model skills creation. This fact creates the need for more research related to the field of energy manager competencies.

The main contribution of this paper is the holistic energy manager skill model, which reflects the current labor market requirements in terms of smart sustainable city concept. It could be used in the process of developing the energy manager competency models in enterprises. It could also be applied as the basis for further elaboration of education programs and training courses.

The process of model creation and validation should be continuous. The enterprises should monitor the current demand with energy managers positions and market changes to fit the model to the developing environment.

Future research could be focused on enlarging the number of countries involved. The created skills model could also be completed with job position groups or divided by energy sector. Moreover, in the future, other emerging technologies could be considered with growing their number.

Funding: The project was financed within the framework of the program of the Minister of Science and Higher Education under the name "Regional Excellence Initiative" in the years 2019-2022; project number 001/RID/2018/19; the amount of financing PLN 10,684,000.00.

Conflicts of Interest: The authors declare no conflict of interest.

\section{Appendix A}

Table A1. Descriptive statistics for demand on energy managers positions by country (see Table 1).

\begin{tabular}{ccccc}
\hline Value & AI & Big Data & Smart City & Sustainability \\
\hline Mean & 830 & 1108.29 & 1340.14 & 919.86 \\
Standard Deviation & 1896.81 & 2002.29 & 3387.02 & 1831.98 \\
Minimum & 0 & 0 & 0 & 10 \\
Maximum & 5107 & 5272 & 9019 & 5051 \\
Range & 5107 & 5272 & 9019 & 5041 \\
Median & 48 & 84 & 32 & 240 \\
Geometric Mean & 0 & 0 & 0 & 189.81 \\
Harmonic Mean & 0 & 0 & 0 & 41.94 \\
Variance & $3,597,872.75$ & $4,009,165$ & $11,471,890$ & $3,356,151.75$ \\
Kurtosis & 6.74 & 3.55 & 6.99 & 6.75 \\
Skewness & 2.59 & 1.97 & 2.64 & 2.58 \\
First Quartile & 12.5 & 34 & 16 & 101.5 \\
Third Quartile & 315 & 1167 & 149 & 467.5 \\
Interquartile Range & 302.5 & 1133 & 133 & 366 \\
Sum & 5810 & 7758 & 9381 & 6439 \\
\hline
\end{tabular}


Table A2. Pearson correlation (see Table 1).

\begin{tabular}{lcccc}
\hline & Column 1 & Column 2 & Column 3 & Column 4 \\
\hline Column 1 & 1 & 0.8178 & 0.8542 & 0.0177 \\
Column 2 & 0.8178 & 1 & 0.7936 & 0.2729 \\
Column 3 & 0.8542 & 0.7936 & 1 & -0.0537 \\
Column 4 & 0.0177 & 0.2729 & -0.0537 & 1 \\
\hline
\end{tabular}

Table A3. Spearman correlation (see Table 1).

\begin{tabular}{ccccc}
\hline & Column 1 & Column 2 & Column 3 & Column 4 \\
\hline Column 1 & 1 & 0.6735 & 0.8265 & 0.7959 \\
Column 2 & 0.6735 & 1 & 0.6429 & 0.7347 \\
Column 3 & 0.8265 & 0.6429 & 1 & 0.7347 \\
Column 4 & 0.7959 & 0.7347 & 0.7347 & 1 \\
\hline
\end{tabular}

Table A4. Covariance matrix (see Table 1).

\begin{tabular}{ccccc}
\hline & Column 1 & Column 2 & Column 3 & Column 4 \\
\hline Column 1 & $3,083,891$ & $3,105,906$ & $5,487,533$ & $61,530.5703$ \\
Column 2 & $3,105,906$ & $3,436,427$ & $5,382,296$ & $1,001,168$ \\
Column 3 & $5,487,533$ & $5,382,296$ & $9,833,048$ & $-333,487.0938$ \\
Column 4 & $61,530.5703$ & $1,001,168$ & $-333,487.0938$ & $2,876,702$ \\
\hline
\end{tabular}

Table A5. Descriptive statistics of the total number of job offers and job offers for executives (see Table 1).

\begin{tabular}{ccc}
\hline Value & Total in Energy Sector & Executives \\
\hline Mean & $58,719.33$ & $19,550.17$ \\
Standard Deviation & $105,097.83$ & $40,661.79$ \\
Minimum & 697 & 297 \\
Maximum & 271,615 & 102,485 \\
Range & 270,918 & 102,188 \\
Median & 15,019 & 3583.5 \\
Geometric Mean & $16,062.55$ & 4058.02 \\
Harmonic Mean & 3537.97 & 1310.59 \\
Variance & $11,045,554,176$ & $1,653,380,864$ \\
Kurtosis & 5.68 & 5.97 \\
Skewness & 2.37 & 2.44 \\
First Quartile & $11,059.25$ & 2526.5 \\
Third Quartile & $33,924.75$ & 4779.25 \\
Interquartile Range & $22,865.5$ & 2252.75 \\
Sum & 352,316 & 117,301 \\
\hline
\end{tabular}

Table A6. Pearson correlation(see Table 1).

\begin{tabular}{ccc}
\hline & Column 1 & Column 2 \\
\hline Column 1 & 1 & 0.8279 \\
Column 2 & 0.8279 & 1 \\
\hline
\end{tabular}

Table A7. Spearman correlation (see Table 1).

\begin{tabular}{ccc}
\hline & Column 1 & Column 2 \\
\hline Column 1 & 1 & 0.4524 \\
Column 2 & 0.4524 & 1 \\
\hline
\end{tabular}


Table A8. Covariance matrix (see Table 1).

\begin{tabular}{ccc}
\hline & Column 1 & Column 2 \\
\hline Column 1 & $9,204,628,480$ & $3,538,010,880$ \\
Column 2 & $3,538,010,880$ & $1,377,816,960$ \\
\hline
\end{tabular}

The results of regression analysis for total offers and offers for executives by countries: Regression line $\hat{y}=0.38437 X-3019.9654$.

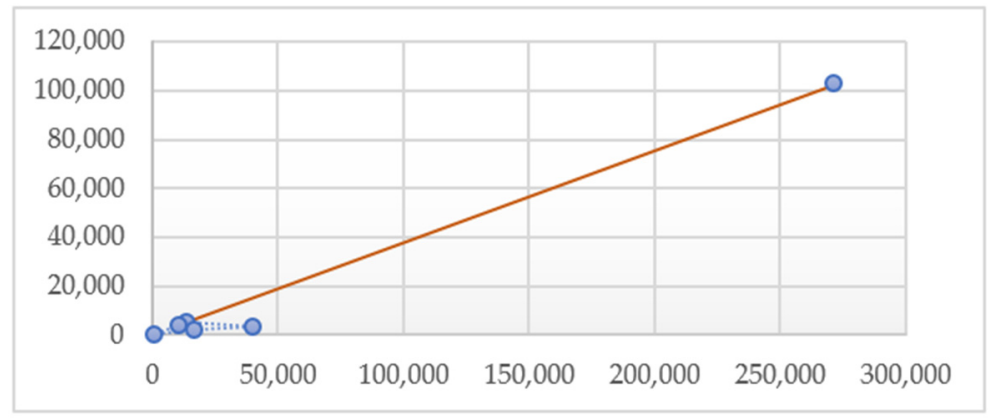

Figure A1. Regression line with the scatter plot.

Sum of $X=352,316$

Sum of $Y=117,301$

Mean $X=58,719.3333$

Mean $Y=19,550.1667$

Sum of squares (SSX) $=55,227,768,717.3333$

Sum of products $(\mathrm{SP})=21,228,068,554.6667$

\section{References}

1. Vezzoli, C.; Ceschin, F.; Osanjo, L.; M’Rithaa, M.K.; Moalosi, R.; Nakazibwe, V.; Diehl, J.C. Energy and sustainable development. In Designing Sustainable Energy for All; Vezzoli, C., Ed.; Springer Nature: London, UK, 2018; pp. 3-22.

2. Calvillo, C.F.; Sánchez-Miralles, A.; Villar, J. Energy management and planning in smart cities. Renew. Sustain. Energy Rev. 2016, 55, 273-287. [CrossRef]

3. Awan, U.; Imran, N.; Muneer, G. Sustainable Development through Energy Management: Issues and Priorities in Energy Savings. Res. J. Appl. Sci. Eng. Technol. 2014, 7, 424-429. [CrossRef]

4. Schirone, L.; Pellitteri, F. Energy Policies and Sustainable Management of Energy Sources. Sustainability 2017, 9, 2321. [CrossRef]

5. Franco, A.; Shaker, M.; Kalubi, D.; Hostettler, S. A review of sustainable energy access and technologies for healthcare facilities in the global south. Sustain. Energy Technol. Assess. 2017, 22, 92-105. [CrossRef]

6. Bringezu, S. Possible Target Corridor for Sustainable Use of Global Material Resources. Resources 2015, 4, 25-54. [CrossRef]

7. Dogaru, V.; Brandas, C.; Cristescu, M. An Urban System Optimization Model Based on $\mathrm{CO}_{2}$ Sequestration Index: A Big Data Analytics Approach. Sustainability 2019, 11, 4821. [CrossRef]

8. Haseeb, M.; Kot, S.; Hussain, H.; Mihardjo, L.; Saługa, P. Modelling the Non-Linear Energy Intensity Effect Based on a Quantile-on-Quantile Approach: The Case of Textiles Manufacturing in Asian Countries. Energies 2020, 13, 2229. [CrossRef]

9. Gonzalez Lima, E.; Kowal Chinelli, C.; Azevedo Guedes, A.L.; Garrido Vazquez, E.; Hammad, A. Smart and Sustainable Cities: The Main Guidelines of City Statute for Increasing the Intelligence of Brazilian Cities Assed Naked Haddad 4 and Carlos Alberto Pereira Soares 1. Sustainability 2020, 12, 1025. [CrossRef]

10. Marinakis, V. Big Data for Energy Management and Energy-Efficient Buildings. Energies 2020, 13, 1555. [CrossRef] 
11. Moses, R.; Devan, P.; Khan, A. Cognitive Technologies: A Technical Primer, Deloitte Insights is an Imprint of Deloitte Development LLC. 2018. Available online: https://www2.deloitte.com/content/dam/insights/ us/articles/4413_Cognitive-technologies-primer/DI_Cognitive-technologies-A-technical-primer\%20.pdf (accessed on 21 August 2020).

12. Womack, D.; Cave, R.; Foden, M.; Stent, M. Exploring the Power of Cognitive IoT Generating Timely Action in Oil and Gas. 2016. Available online: https:/www.ibm.com/industries/geos/chemicalspetroleum/assets/ IBM_Whitepaper_Exploring_the_power_of_cognitive_IoT.pdf (accessed on 29 August 2020).

13. A New Natural Resource: Your Cognitive Future in the Oil and Gas Industry; IBM Institute for Business Value: Somers, NY, USA, 2016.

14. Coyne, B. 2019 Outlook: Energy Managers Outline Key Challenges, The Energyst. Available online: https://theenergyst.com/energy-managers-2019-outlook/ (accessed on 3 January 2019).

15. Michelucci, F.V.; De Marco, A.; Tanda, A. Defining the Role of the Smart-City Manager: An Analysis of Responsibilities and Skills. J. Urban Technol. 2016, 23, 23-42. [CrossRef]

16. International Telecommunication Union. Report of the Smart Sustainable Development Model (SSDM), SSDM Advisory Board; International Telecommunication Union: Geneva, Switzerland, 2018; License: CC BY-NC-SA 3.0 IGO. Available online: https:/www.itu.int/dms_pub/itu-d/opb/str/D-STR-SSDM.01-2018-PDF-E.pdf (accessed on 20 August 2020).

17. Pérez González, D. Energy Economics and Innovation of Smart Cities. 2020. Available online: https://www. mdpi.com/journal/energies/special_issues/Energy_Economics_and_Innovation_of_Smart_Cities (accessed on 23 September 2020).

18. Pilipczuk, O. Toward Cognitive Management Accounting. Sustainability 2020, 12, 5108. [CrossRef]

19. Patterson, F.; Tavabie, A.; Denney, M.; Kerrin, M.; Ashworth, V.; Koczwara, A.; MacLeod, S. A new competency model for general practice: Implications for selection, training, and careers. Br. J. Gen. Pract. 2013, 63, 331-338. [CrossRef]

20. Suhairom, N.; Musta'amal, A.; Amin, N.; Johari, N. The Development of Competency Model and Instrument for Competency Measurement: The Research Methods. Procedia Soc. Behav. Sci. 2014, 152, 1300-1308. [CrossRef]

21. Lucia, A.; Lepsinger, R. A review of The Art and Science of Competency Models. Acad. Manag. Learn. Educ. 2013, 2, 210-212.

22. Marrelli, A.; Tondora, J.; Hoge, M. Strategies for developing competency models. Adm. Policy Ment. Heal. 2005, 32, 533-561. [CrossRef]

23. Barenji, R.; Hashemipour, M.; Guerra-Zubiaga, D.; Camarinha-Matos, L.M.; Tomic, S.; Graça, P. (Eds.) Toward a Modeling Framework for Organizational Competency. In Stochastic Differential Systems; Springer Science and Business Media LLC: Berlin/Heidelberg, Germany, 2013; Volume 394, pp. 142-151.

24. Prifti, L.; Knigge, M.; Kienegger, H.; Krcmar, H. A Competency Model for “Industrie 4.0” Employees. In Proceedings of the 2017 Internationalen Tagung Wirtschaftsinformatik, St. Gallen, Switzerland, 12-15 February 2017; pp. 46-60.

25. Ejaz, W.; Naeem, M.; Shahid, A.; Anpalagan, A.; Jo, M. Efficient Energy Management for the Internet of Things in Smart Cities. IEEE Commun. Mag. 2017, 55, 84-91. [CrossRef]

26. Refaat, S.S.; Abu-Rub, H.; Mohamed, A. Big data, better energy management and control decisions for distribution systems in smart grid. In Proceedings of the IEEE International Conference on Big Data (Big Data), Washington, DC, USA, 5-8 December 2016; pp. 3115-3120. [CrossRef]

27. Jiang, H.; Wang, K.; Wang, Y.; Gao, M.; Zhang, Y. Energy big data: A survey. IEEE Access 2016, 4, 3844-3861. [CrossRef]

28. Nafi, N.; Ahmed, K.; Gregory, M.; Datta, M. A survey of smart grid architectures, applications, benefits and standardization. J. Netw. Comput. Appl. 2016, 76, 23-36. [CrossRef]

29. Thai, M.T.; Wu, W.; Xiong, H. (Eds.) Big Data in Complex and Social Networks; CRC Press: Boca Raton, FL, USA, 2016.

30. Michelangelo, C.; Nunziato, C.; Roberto, C.; Pietro, D.; Donato, M.; Gaspare, M.; Elio, M.; Camillo, P. Big data techniques for renewable energy market. In Proceedings of the 22nd Italian Symposium on Advanced Database Systems, SEBD, Naples, Italy, 16-18 June 2014; pp. 369-377.

31. Amazon, What Is Dash Replenishment. Available online: https://developer.amazon.com/en-US/alexa/dashservices (accessed on 25 September 2020). 
32. Microsoft, What Is Cloud Computing? A Beginner's Guide-Microsoft Azure. Available online: https: //azure.microsoft.com/en-in/overview/what-is-cloud-computing/ (accessed on 18 September 2020).

33. Zhou, K.; Yang, S. Understanding household energy consumption behavior: The contribution of energy big data analytics. Renew. Sustain. Energy Rev. 2016, 56, 810-819. [CrossRef]

34. Big Data and Energy: A Clear Synergy, Wharton University of Pennsylvania. Available online: http: //knowledge.wharton.upenn.edu/article/the-big-data-and-energy-synergy/ (accessed on 12 September 2014).

35. Schuelke-Leech, B.A.; Barry, B.; Muratori, M.; Yurkovich, B.J. Big Data issues and opportunities for electric utilities. Renew. Sustain. Energy Rev. 2015, 52, 937-947. [CrossRef]

36. Grolinger, K.; L'Heureux, A.; Capretz, M.; Seewald, L. Energy forecasting for event venues: Big data and prediction accuracy. Energy and Build. 2015, 112, 222-233. [CrossRef]

37. Martínez-Álvarez, F.; Troncoso, A.; Riquelme, J. Data Science and Big Data in Energy Forecasting. Energies 2018, 11, 3224. [CrossRef]

38. Gokten, S.; Kucukkocaoglu, G. Energy Management for Sustainable Development; IntechOpen: London, UK, 2018.

39. Bhattacharya, T.; Bhattacharya, A.; Mclellan, B.; Tezuka, T. Sustainable smart city development framework for developing countries. Urban Res. Pract. 2018, 13, 180-212. [CrossRef]

40. Zhou, K.; Fu, C.; Yang, S. Big data driven smart energy management: From big data to big insights. Renew. Sustain. Energy Rev. 2016, 56, 215-225. [CrossRef]

41. Silva, B.; Khan, M.; Han, K. Towards sustainable smart cities: A review of trends, architectures, components, and open challenges in smart cities. Sustain. Cities Soc. 2018, 38, 697-713. [CrossRef]

42. O’Dwyer, E.; Pan, I.; Acha, S.; Shah, N. Smart energy systems for sustainable smart cities: Current developments, trends and future directions. Appl. Energy 2019, 237, 581-597. [CrossRef]

43. Sustainable Cities and Society (SCS) Journal. Available online: https://www.journals.elsevier.com/sustainablecities-and-society (accessed on 18 August 2020).

44. Bibri, S.E. On the sustainability of smart and smarter cities in the era of big data: An interdisciplinary and transdisciplinary literature review. J. Big Data 2019, 6, 25. [CrossRef]

45. Bibri, S.E. A foundational framework for smart sustainable city development: Theoretical, disciplinary, and discursive dimensions and their synergies. Sustain. Cities Soc. 2018, 38, 758-794. [CrossRef]

46. Gaska, K.; Generowicz, A. SMART Computational Solutions for the Optimization of Selected Technology Processes as an Innovation and Progress in Improving Energy Efficiency of Smart Cities. Energies 2020, 13, 3338. [CrossRef]

47. Díaz-Díaz, R.; Muñoz, L.; Pérez-González, D. The Business Model Evaluation Tool for Smart Cities: Application to Smart Santander Use Cases. Energies 2017, 10, 262. [CrossRef]

48. Smart City Lighting Systems. Energies. 2020. Available online: https://www.mdpi.com/journal/energies/ special_issues/city_lighting_systems (accessed on 20 March 2020).

49. Toli, A.M.; Murtagh, N. The Concept of Sustainability in Smart City Definitions. Front. Built Environ. 2020, 6, 77. [CrossRef]

50. Pérez-González, D.; Diaz-Diaz, R. Public Services Provided by ICT in the Smart City Environment: The Case of Spanish Cities. J. Univers. Comput. Sci. 2015, 21, 248-267.

51. Díaz-Díaz, R.; Muñoz, L.; Pérez-González, D. Business model analysis of public services operating in the smart city ecosystem: The case of Smart Santander. J. Future Gener. Comput. Syst. 2017, 76, 198-214. [CrossRef]

52. Energy Star, Guidelines for Energy Management, U.S. Environmental Protection Agency, Minister of Natural Resources. 2019. Available online: https://www.energystar.gov/sites/default/files/buildings/tools/ Guidelines\%20for\%20Energy\%20Management\%206_2013.pdf (accessed on 21 August 2020).

53. Maier, S.; Narodoslawsky, M. Optimal Renewable Energy Systems for Smart Cities. Computer Aided Chemical Engineering 2014, 33, 1849-1854.

54. Villa-Arrieta, M.; Sumper, A. Contribution of Smart Cities to the Energy Sustainability of the Binomial between City and Country. Appl. Sci. 2019, 9, 3247. [CrossRef]

55. Oliviera Fernandes, E.; Meeus, L.; Leal, V.; Azevedo, I.; Delarue, E.; Glachant, J.-M. Smart Cities Initiative: How to Foster a Quick Transition Towards Local Sustainable Energy Systems; European University Institute: Firenze, Italy, 2011. 
56. Lund, H.; Werner, S.; Wiltshire, R.; Svendsen, S.; Thorsen, J.E.; Hvelplund, F.; Mathiesen, B.V. 4th Generation District Heating (4GDH): Integrating smart thermal grids into future sustainable energy systems. Energy 2014, 68, 1-11. [CrossRef]

57. Tanda, A.; De Marco, A. Business Model Framework for Smart City Mobility Projects. IOP Conf. Series Mater. Sci. Eng. 2019, 471, 092082. [CrossRef]

58. Lee, H.; Hancock, M.G.; Hu, M.C. Towards an effective framework for building smart cities: Lessons from Seoul and San Francisco. Technol. Forecast. Soc. Chang. 2014, 89, 80-99. [CrossRef]

59. Lee, J.-G.; Kang, M. Geospatial Big Data: Challenges and Opportunities. Big Data Res. 2015, $2,74-81$. [CrossRef]

60. Li, S.; Dragicevic, S.; François, A.; Sester, M.; Winter, S.; Coltekin, A.; Pettit, C.; Jiang, B.; Haworth, J.; Stein, A.; et al. Geospatial Big Data Handling Theory and Methods: A Review and Research Challenges. ISPRS J. Photogramm. Remote. Sens. 2016, 115, 119-133. [CrossRef]

61. Kamali, C.; Augasta, M.; Kamali, C.; Augasta, M. Geo-Spatial Big Data Analysis: An Overview. Int. J. Trend Res. Dev. (IJTRD) 2017. Available online: http://www.ijtrd.com/papers/IJTRD12092.pdf (accessed on 18 September 2020).

62. Breunig, M.; Bradley, P.E.; Jahn, M.; Kuper, P.; Mazroob, N.; Rösch, N.; Al-Doori, M.; Stefanakis, E.; Jadidi, M. Geospatial Data Management Research: Progress and Future Directions. ISPRS Int. J. Geo-Inf. 2020, 9, 95. [CrossRef]

63. Papageorgiou, K.; Carvalho, G.; Papageorgiou, E.; Bochtis, D.; Stamoulis, G. Decision-Making Process for Photovoltaic Solar Energy Sector Development using Fuzzy Cognitive Map Technique. Energies 2020, 13, 1427. [CrossRef]

64. Hu, H.; Zhang, H.; Yu, H.; Chen, Y.; Jafarian, J. Energy-efficient design of channel sensing in cognitive radio networks. Comput. Electr. Eng. 2015, 42, 207-220. [CrossRef]

65. Shi, Z.; Teh, K.C.; Li, K.H. Energy-efficient joint design of sensing and transmission durations for protection of primary user in cognitive radio systems. IEEE Commun. Lett. 2013, 17, 565-568. [CrossRef]

66. Rinaldi, S.; Bellagente, P.; Ciribini, A.; Tagliabue, L.C.; Poli, T.; Mainini, A.G.; Speroni, A.; Cadena, J.D.B.; Spagnolo, S.L. A Cognitive-Driven Building Renovation for Improving Energy Efficiency: The Experience of the ELISIR Project. Electronics 2020, 9, 666. [CrossRef]

67. Pilipczuk, O. Cognitive Visualization in Management; Group IVG: Szczecin, Poland, 2018.

68. Goralski, M.; Tan, T.K. Artificial intelligence and sustainable development. Int. J. Manag. Educ. 2020, 18, 100330. [CrossRef]

69. Pedemonte, V. AI for Sustainability: An Overview of AI and The SDGs to Contribute to the European Policymaking. 2020. Available online: https://ec.europa.eu/futurium/en/system/files/ged/vincentpedemonte_ai-for-sustainability_0.pdf (accessed on 1 March 2020).

70. Vinuesa, R.; Azizpour, H.; Leite, I.; Balaam, M.; Dignum, V.; Domisch, S.; Felländer, A.; Langhans, S.D.; Tegmark, M.; Nerini, F.F. The role of artificial intelligence in achieving the Sustainable Development Goals. Nat. Commun. 2020, 11, 233. [CrossRef]

71. Hussain, H.I.; Slusarczyk, B.; Kamarudin, F.; Thaker, H.M.T.; Szczepanska-Woszczyna, K. An Investigation of an Adaptive Neuro-Fuzzy Inference System to Predict the Relationship among Energy Intensity, Globalization, and Financial Development in Major ASEAN Economies. Energies 2020, 13, 850. [CrossRef]

72. Accenture. Available online: https://www.accenture.com/us-en/blogs/blogs-cognitive-computing-gamechanger-oil-gas (accessed on 12 September 2020).

73. Mataloto, B.; Ferreira, J.C.; Cruz, N. LoBEMS-IoT for Building and Energy Management Systems. Electronics 2019, 8, 763. [CrossRef]

74. Bedi, G. Internet of Things and Intelligent Technologies for Efficient Energy Management in a Smart Building Environment (2018). All Dissertations. 2411. Available online: https://tigerprints.clemson.edu/all_ dissertations/2411 (accessed on 18 June 2019).

75. Hossein Motlagh, N.; Mohammadrezaei, M.; Hunt, J.; Zakeri, B. Internet of Things (IoT) and the Energy Sector. Energies 2020, 13, 494. [CrossRef]

76. Arshad, R.; Zahoor, S.; Shah, M.A.; Wahid, A.; Yu, H. Green IoT: An Investigation on Energy Saving Practices for 2020 and Beyond. IEEE Access 2017, 5, 15667-15681. [CrossRef]

77. Osifeko, M.O.; Hancke, G.P.; Abu-Mahfouz, A.M. Artificial Intelligence Techniques for Cognitive Sensing in Future IoT: State-of-the-Art, Potentials, and Challenges. J. Sens. Actuator Netw. 2020, 9, 21. [CrossRef] 
78. Kafle, Y.; Mahmud, K.; Morsalin, S.; Town, G. Towards an internet of energy. In Proceedings of the 2016 IEEE International Conference on Power System Technology (POWERCON), Wollongong, Australia, 28 September-1 October 2016; pp. 1-6.

79. William, H.; Mashburn, P.E. The changing role of the energy manager, Energy Developments: New Forms, Renewables, Conservation. In Proceedings of the ENERGEX '84, The Global Energy Forum, Regina, SK, Canada, 14-19 May 1984; pp. 945-948.

80. Aspenson, R.L. Skills of the Energy Manager. Energy Econ., Policy Manage. Journal Volume: 2:2 United States. Available online: https://www.osti.gov/biblio/6665309 (accessed on 21 August 2020).

81. Georgescu-Roegen, N. Energy Analysis and Economic Valuation. South. Econ. J. 1979, 45, 1023-1058. [CrossRef]

82. Dalton, L.; D'Netto, B.; Bhanugopan, R. Cultural diversity competencies of managers in the Australian energy industry. J. Dev. Areas 2015, 49, 387-394. [CrossRef]

83. Ballini, F.; Ölçer, A.I. Energy Manager Role in Ports. In Trends and Challenges in Maritime Energy Management; Ölçer, A., Kitada, M., Dalaklis, D., Ballini, F., Eds.; WMU Studies in Maritime Affairs; Springer: Cham, Switzerland, 2018; Volume 6.

84. Ricciardi, F.; Za, S. Smart City Research as an Interdisciplinary Crossroads: A Challenge for Management and Organization Studies. In From Information to Smart Society; Mola, L., Pennarola, F., Za, S., Eds.; Springer: Berlin/Heidelberg, Germany, 2014; pp. 163-171.

85. Goulden, M.; Spence, A. The role of the Facilities Manager in organisational energy use. Energy Policy 2015, 85, 280-287. [CrossRef]

86. EL-Shimy, M. Fundamentals of Energy Management and Energy Managers-A Technical Report and a Short Course. 2018. Available online: https://www.researchgate.net/publication/322941258_Fundamentals_ of_Energy_Management_and_Energy_Managers_-_A_technical_report_and_a_short_course (accessed on 20 September 2020). [CrossRef]

87. Clean Energy Ministerial, Global Superior Energy Performance Partnership, Knowledge and Skills Needed to Implement Energy Management Systems in Industry and Commercial Buildings, Ancillary Requirements \& Skills. 2013. Available online: http://www.cleanenergyministerial.org/sites/default/files/2018-08/Knowledge_ Skills_EnMS_Implementation_Report.pdf (accessed on 20 September 2020).

88. Hardcastle, A.; Love, C.; Zeiger Hanson, S. Energy Efficiency Management Skills for Manufacturing: Implications for Workforce Development in Washington State; Washington State University Energy Program; Workforce Training \& Education Coordinating Board: Olympia, WA, USA, 2013.

89. Industry \& Production 4.0 Energy Manager Curriculum \& Teachers. Available online: http://learn.skillman. eu/pluginfile.php/1581/mod_resource/content/1/WP4.2.3\%20-\%20Joint\%20European\%20Curricula_

\%20Final\%20version\%20-\%20Curriculum\%20Industry\%20Production\%204.0\%20Energy\%20Manager.pdf (accessed on 21 September 2020).

90. Skills Future. 2018. Available online: https://www.skillsfuture.sg/ (accessed on 17 August 2020).

91. ARCADIS. Energy Management Handbooks, ISO 50001. Available online: https://www.arcadis.com/media/ 2/E/C/\%7B2EC9983D-2558-49A9-BEDF-69C1558ADAD4\%7DEnMS\%20Handbook\%202019.pdf (accessed on 21 September 2020).

92. Taking Responsibility for Energy Management. Available online: https://www.energy.gov.au/sites/default/ files/6-taking-responsibility-for-energy-management1.pdf (accessed on 18 September 2020).

93. Natural Resources Canada, Energy Management Training Primer, Minister of Natural Resources. 2016. Available online: https://www.nrcan.gc.ca/sites/www.nrcan.gc.ca/files/oee/files/pdf/publications/commercial/ EMT_Primer_en.pdf (accessed on 18 August 2020).

94. Rizzi, F.; Annunziata, E.; Frey, M. The Relationship between Organizational Culture and Energy Performance: A Municipal Energy Manager Level Study. Bus. Strategy Environ. 2018, 27, 694-711. [CrossRef]

95. Zarzecki, D.; Jabłoński, M. Sustainable Value Management; MDPI: Basel, Switzerland, 2019.

96. Kot, S. Sustainable Supply Chain Management in Small and Medium Enterprises. Sustainability 2018, 10, 1143. [CrossRef]

97. Smitha, S.D.; Chacko, F.M. Intelligent energy management in smart and sustainable buildings with multi-agent control system. In Proceedings of the 2013 International Multi-Conference on Automation, Computing, Communication, Control and Compressed Sensing (iMac4s), Kottayam, Indian, 22-23 March 2013; pp. 190-195. 
98. The European Commission Joint Research Centre. The Impact of COVID Confinement Measures in EU Labor Market. 2020. Available online: https://ec.europa.eu/jrc/sites/jrcsh/files/jrc.120585_policy.brief_impact. of_.covid-19.on_.eu-labour.market.pdf (accessed on 21 August 2020).

99. Guerrero, D.; De los Ríos, I. Professional Competences: A Classification of International Models. Procedia Soc. Behav. Sci. 2012, 46, 1290-1296. [CrossRef]

100. World Economic Forum. Skills Stability. Available online: https://reports.weforum.org/future-of-jobs-2016/ skills-stability/ (accessed on 21 August 2020).

101. Kukuła, K. Dynamics of Producing Renewable Energy in Poland and EU-28 Countries within the Period of 2004-2012. Folia Oeconomica Stetin. 2015, 15, 167-175. [CrossRef]

102. World Economic Forum. Drivers of Change. Available online: https://reports.weforum.org/future-of-jobs2016/drivers-of-change/ (accessed on 18 September 2020).

103. European Comission Website. Energy 2020-A Strategy for Competitive, Sustainable and Secure Energy; Publications Office of the European Union: Luxembourg, 2011; Available online: https:/ec.europa.eu/energy/ sites/ener/files/documents/2011_energy2020_en_0.pdf (accessed on 21 August 2020).

Publisher's Note: MDPI stays neutral with regard to jurisdictional claims in published maps and institutional affiliations.

(C) 2020 by the author. Licensee MDPI, Basel, Switzerland. This article is an open access article distributed under the terms and conditions of the Creative Commons Attribution (CC BY) license (http://creativecommons.org/licenses/by/4.0/). 